\title{
«ABRILS ISSIA». EL MÓN D’AHIR \\ SEGONS RAMON VIDAL DE BESALÚ
}

\author{
Anton M. Espadaler \\ Universitat de Barcelona \\ aespadaler@ub.edu
}

\begin{abstract}
Resum
L'article defensa que el temps ideal en què l'art de trobar exercia la seva major funció i influència no és sentit per Ramon Vidal de Besalú com un temps mític, sinó com un temps històric. El poema abordaria la seva crisi i n’assenyalaria les causes, les principals de les quals foren la davallada econòmica dels usuals protectors de la lírica trobadoresca i, molt especialment, la pressió eclesiàstica, en particular sobre les dones, en el clima enrarit dels anys que envolten la croada contra els albigesos.
\end{abstract}

\section{Paraules clau}

Ramon Vidal de Besalú, Abrils issia, lírica trobadoresca, ideologia cortesa, anticlericalisme.

\begin{abstract}
The article discusses that the ideal time in which troubadour art exerted its most important role and influence is not considered by Ramon Vidal de Besalú as a mythic but as a historical time. The poem Abrils issia deals with the crisis and points out its causes, which were mainly the economic downturn of the protectors of troubadour poetry, as well as the ecclesiastical pressure, particularly on women in the rarefied atmosphere in the time of the Albigensian crusade.
\end{abstract}

\section{Keywords}

Ramon Vidal de Besalú, Abrils issia, troubadour lyrics, courtly arts, anticlericalism. 
Escrivia John W. Baldwin en iniciar l'examen de l'estat de la joglaria al nord de França, partint del roman de Guillaume de Dole de Jean Renart: "el fet que el temps i l'espai del relat sigui el contemporani de l'autor i que aquest l'ompli amb figures històriques ben conegudes pels seus contemporanis, o sia el fet de collocar la història de ficció en un marc realista, m’empeny a usar la novel.la de Jean

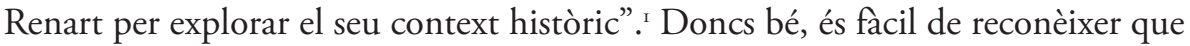
els vincles amb la realitat, amb el mateix recurs d'esmentar personatges històrics perfectament identificats, i a més fer-ho en gran nombre, són superiors en el cas de Ramon Vidal. I aplicant el mateix criteri que l'estudiós americà, hom pot pensar que Ramon Vidal retrata un estat de coses que pertany a un temps concret, i a una àrea concreta. L'àrea fóra la que comprèn els viatges del joglar. Des de la cort del Dalfí d'Alvèrnia a les corts del nord d'Itàlia i de Castella, i sobretot les corts, majoritàriament d'una noblesa vinculada en graus diversos amb l'entourage reial, tant d'Aragó com del Rosselló, com d'una Catalunya encara ancorada a les dues faldes del Pirineu: el territori radicat més al sud és el d'Arnau de Castellvell, al Penedès. Un gruix important d'aquests personatges apareix al costat del rei Alfons a la razo del poema De chantar méera laissatz de Peire Vidal (Garcia Romeu, Miquel de Luesia, Albert de Castellvell, Ramon Galceran de Pinós, Arnau de Castellbò), molts dels quals formaven part també de la comitiva que acompanyà Pere el Catòlic quan va visitar Raimon vi de Tolosa el gener de I2I3. ${ }^{2}$ La proximitat al rei, de fet als reis, em sembla una dada digna de ser tinguda en compte. Això podria explicar, per exemple, l'oblit total de Guillem de Berguedà, reforçat, és clar, pel lligam de Ramon Vidal amb els Mataplana (recordin-se els violents sirventesos contra Ponç de Mataplana), i l'oblit de la casa de Cabrera, en conflicte amb el rei Pere pel comtat d'Urgell, després que Guerau de Cabrera -l'autor del Cabra joglar, segons la datació de Cingolani- ${ }^{3}$ ocupés el comtat entre 1209 i I2II, fins a ser-ne desposseït.

Pel que fa al temps, o sia a la datació de l'obra — com tot el que conservem a nom de Ramon Vidal—, la resposta ara com ara només pot ser aproximada. La gran majoria dels personatges esmentats van viure a cavall dels regnats d'Alfons el Trobador i de Pere el Catòlic. Molts participaren a la batalla de Las Navas i pràcticament els mateixos a la de Muret. El poema no conté, però, cap referència ni a una batalla ni a l'altra.

I J. W. BALDwin, “The Image of Jongleur in Northern France around I200”, Speculum, 72 (1997), pp. $635-663$ (638).

2 M. Alvira, Muret I2I3, Madrid, 2008, p. 56.

3 S. M. Cingolani, "The sirventes-ensenhamen of Guerau de Cabrera: A Proposal for a new Interpretation", Journal of Hispanic Research, I (I993), pp. I9I-20I. 
Conté, tanmateix, una curiosa història, qualificada de sermó (v. 970), exposada pel personatge més allunyat de tots de les fronteres amb els moros, com és el Dalfí d'Alvèrnia. Es tracta d'una paràbola que enalteix l'esperit bèl.lic i moral dels almohades — uns fonamentalistes islàmics guiats per l'esperit de la gihaddavant dels almoràvits, els quals en haver afluixat el rigor i l'esperit bèl-lic es veieren conquerits pel que era una confederació de tribus berbers, pertanyents sobretot al tronc dels masmudes, vingudes del sud del Magrib.. Ibn Jubair de Xàtiva, que visqué en aquesta mateixa època, posant en relleu l'alenada rigorista i agressiva que els definia, els presentava com als restauradors de la vertadera fe, l'espasa dels quals havia de dur el respecte a les "sacrosantes prohibicions d'Al.là", fins al punt de dir que "no hi ha veritable islam sinó als països del Magrib".

Aquesta història ve marcada per dos almassors, o sia dos cabdills moros, famosos pel seu valor, en dos moments diferents en el domini musulmà de la península ibèrica. Aquest substantiu es forma, com és evident, a partir del cèlebre Al Mansur (el Victoriós), conqueridor de Barcelona el 985, el record del qual és possible que sigui evocat pel Dalfí per indicar l'inici del domini almoràvit —els marabetins. Pel que fa al segon, no oblidaria que els almohades van atènyer el seu zenit amb un altre Al Mansur el II95: el califa Abu Yusuf Yáqub Al Mansur (II84-II98), cap de l'exèrcit que va vèncer la batalla d'Alarcos el I9 de juliol d'aquell any. ${ }^{6}$ Això em fa pensar que mentalment som encara sota la forta impressió ocasionada per la derrota d'Alarcos, que no oblidem que va deixar una empremta molt profunda en la consciència col-lectiva, ${ }^{7}$ com demostra la cançó de croada de Folquet de Marsella Hueimais no.y conosc razo i la razo que l'acompanya, ${ }^{8}$ escrites sota l'impacte de la derrota del "bos reis Anfos de Castela", o la de Gavaudan marcada pels èxits posteriors d'Al Mansur Senhors, per los nostres peccatz. ${ }^{9}$ I que encara no s'hi albira el clima que durà a la victòria esclatant de Las Navas el I6 de juliol del I2I2, en la qual tingué un paper de primer ordre el rei Pere d'Aragó, i en sortí derrotat el temut, odiat i finalment ridiculitzat califa Abu 'Abd Allah Muhammad ben Yáqub al-Nasir (II99-I2I3), que amb el significat d'emir dels creients rebia el títol d'al-Amir al-Mu’minin, romanitzat en Miramamolin. ${ }^{10}$ En conseqüència, entenc

4 F. García Fitz, Las Navas de Tolosa, Madrid, p. 302.

5 P. Guixà i L. Belkacemi, Els viatges d'Ibn Jubair, Barcelona, 2008, p. Ioo.

6 J. Benelhaj Soulami, "La batalla de Alarcos en la mitología árabe", a R. IzQuierdo i F. RuIz (coords.), Alarcos II95. Actas del Congreso Intrnacional Conmemorativo del VIII Centenario de la Batalla de Alarcos, Cuenca, 1996, pp. 284-288 (285).

7 F. García Fitz, Las Navas de Tolosa, Madrid. p. 268.

8 S. Stronski, Le troubadour Folquet de Marseille, Ginebra, 1968, xix, 7; S. Guida, Canzoni di crociata, Parma, I992, XXXII.

9 S. Guida, Il trovatore Gavaudan, Mòdena, I979, V; Id., Canzoni di crociata, xxxiII.

io M. Alvira, "De Alarcos a las Navas de Tolosa: Idea y realidad de los orígenes de la batalla de 
que la problemàtica a què fa referència Ramon Vidal se situa, com al Guillaume de Dole, també al voltant del I200. Posem, com a punt de partença, que entre II95 i I2IO, comptant que el zenit del poder almohade se situa el I207, ${ }^{\text {II }}$ quan les coses comencen a canviar d'una manera definitiva després que no es renovessin les treves que castellans i almohades mantenien des de $1197,{ }^{12}$ però en què la flota d'al-Andalus llançà agressives falconades contra el litoral català. I abans que la tensió d'una guerra imminent s'apoderés de tot Occitània i fos percebuda a Aragó com un procés que determinava el seu esdevenidor, almenys el més immediat. En aquest sentit, l'intent de datar l'obra en funció del punt de vista que proporciona la croada antialbigesa em sembla molt problemàtic, ja que no s'hi fa la més petita menció. Cert és, com ha escrit Vatteroni, que la producció dedicada a la croada abans de Muret és quasi nul.la, ${ }^{13}$ però així i tot si el conflicte que origina Abrils issia fos aquest, s'hauria d'explicar com es poden escriure gairebé I800 versos sense que aparegui un sol francès, mentre l'aspecte religiós de l'afer sembla llunyà o indiferent. I n'és la prova que Ramon Vidal lloa la contribució a l'edificació d'esglésies per part de nobles catalanes, però no per això deixa de lloar també notables capitostos de l'heretgia com Ponç de Vernet o Bertran de Saissac. Semblaria que Ramon Vidal era de la mateixa opinió que el cavaller Pons d'Ademar el qual, segons conta Guilhem de Puy-Laurens, quan el bisbe de Tolosa Folc — $\mathrm{O}$ sia l'antic trobador Folquet de Marsella — li demanà per què no havien foragitat els herètics de les seves terres, va respondre: "No podíem; ens havíem criat amb ells, hi teníem gent molt propera, i vèiem que vivien honestament" ${ }^{14}$ En qualsevol cas, és segur que Ramon Vidal mai no afirmaria, com fa Andreu el Capellà al De amore, que l'amor s'acaba quan algú "in fide catholica deprehendatur errare". ${ }^{\text {Is }}$ Potser no és sobrer de recordar, en la perspectiva exclusivament laica en què se situa Ramon Vidal, que la difusió de l'heretgia, com ha escrit Jordi Ventura, "serví a Catalunya els interessos dels feudals en la seva lluita contra l'església". ${ }^{16}$

Potser podríem afinar una mica més quant a la cronologia. El vers ara es vengut us perdos, pot fer referència, segons apunta Monica Calzolari en un tre-

I2I2", a Alarcos $1195 \ldots$, , pp. 250-264.

i F. García Fitz, "La Batalla en su contexto estratégico. A propósito de Alarcos", a Alarcos I995..., p. 139 .

I2 Alvira, "De Alarcos a las Navas de Tolosa...", p. 257.

I3 S. Vatteroni, "Le corti della Francia meridionale", a Lo spazio letterario del medioevo, 2. Il medioevo volgare. I. La produzione del testo, Roma, 200I, pp. 353-398 (378).

I4 G. De Puy-Laurens, Histoire de l'expédition contre les albigeois, Clermont-Ferrand, 2004, viII, p. 26.

I5 I. Creixell, Andreas capellanus. De Amore, Barcelona 1985, II, IV.

I6 J. Ventura, Els heretges catalans, Barcelona, I976, p. 65. 
ball excel-lent, a la perdonansa (per dir-ho com Guilhem Figueira) atorgada als croats anticàtars, la qual cosa, però, la duu a datar amb posterioritat al I2I3. A les terres d'Aragó, l'únic perdó possible després de I2I3 és l'ofert als cavallers que van combatre contra els croats, com Gastó de Bearn, per esmentar un personatge del nostre text, el qual fou perdonat no a l'engròs, sinó després d'un procés que pel que explica Almudena Blasco s'endevina personalitzat. ${ }^{17}$ El perdó acabat d'arribar, si és que té alguna cosa a veure amb Innocent III, crec que té més sentit si fa referència al moment de la proclamació de la croada. Si fos així, tindríem una de les dates més segures: Io de març de I208.

Entenc que la problemàtica debatuda a Abrils issia, que és comuna a tota l'àrea esmentada, hauria de deixar-se analitzar també i amb major nitidesa, perquè és major la informació, a Catalunya. I possiblement perquè a Catalunya l'afer es presentava amb trets més punyents. Crec, doncs, que el context assenyalat de manera preferent és el catalano-occità, i que va d'acord, a més, amb l'òptica catalanocèntrica de què parla Martí Aurell: o sia el resultat de posseir la consciència que el poder reial, l'obsessió d'Alfons I, fa del regne d'Aragó, el nucli aglutinador de la política i la cultura meridionals. Es tracta, doncs, d'esbrinar, fins on sigui possible, allò que apuntava Maria Luisa Meneghetti sobre Abrils issia: "Se ne deve insomma dedurre che, probabilmente non molti anni dopo la morte di Alfonso II (II96), è successo qualcosa che ha distolto la maggior parte dei grandi signori provenzali e catalani da un'ormai consueta attenzione per la poesia cortese. Che si tratti di stanchezza nei confronti di un genere letterario - e di un modello comportamentale - da molti ritenuto troppo impegnativo, di obiettive difficoltà economiche che chiudevano anche le borse più fornite, delle preocupazioni per le prime nubi della tempesta antialbigese, che si stava profilando all'orizzonte, è difficile dirlo" ${ }^{18}$ El més probable és que sigui de tot una mica.

Em pregunto d'entrada pel primer protagonista de l'obra, el mateix Ramon Vidal, autoretratat a la plaça de Besalú, "solo e pensoso" (anoten Limentani i Tavani), però "per amor un pauc embroncx" (v. 9). Entenc per això mateix que Ramon Vidal no és el trobador jubilat, que viu al marge d'una activitat literària definitivament deixada enrere, sinó algú encara actiu, per més que el seu paper ens el faci percebre com una autoritat tan selecta i qualificada que ja sembla haver passat a la posteritat. Altrament aquest desassossec amorós no tindria cap sentit. D'altra banda, la naturalesa d'un poema que es construeix com la llarga resposta a una pregunta, fa que hàgim de donar per sabut que Ramon Vidal era per al seu públic algú amb coneixements suficientment provats com per respondre-la, la

I7 A. Blasco, "Gastó vi de Bearn i Montcada i la Croada", a Col-loqui d'Història Medieval Occitano-Catalana, Eurocongrés 2000, Barcelona, 2004, pp. I4I-I55.

I8 M. L. Meneghetti, Il pubblico dei trovatori, Torí, I992, pp. 47-48. 
qual cosa va d'acord amb el caràcter teòric dels fragments lírics conservats en els poemes narratius.

El segon protagonista és el joglaret, anomenat així per un eco especular amb el poema de Giraut de Bornelh Per solatz reveilhar, i designat amb un diminutiu que a So fo e.l temps es reserva al trobador Alegret, i al portador de noves a la cort de Mataplana. Cal dir que la datació del poema de Giraut de Bornelh, que potser és el darrer de la seva producció, la qual cosa conferiria a la represa un alt valor, continua sent un enigma. S'ha dit i repetit que Giraut exhala el caire d'una lamentació pel món deixat enrere, però se sol oblidar que allò que justifica un innegable enyor no és altra cosa que la protesta pel poder dels lladres. També s'ha sostingut que el parlament del joglaret de Ramon Vidal és un exercici de nostàlgia per un món perdut.

El tercer és un personatge d'un relleu polític més aviat discret, amb poca capacitat de maniobra, lligat de peus i mans entre l'expansionisme del rei Felip August i els moviments tàctics de Ricard Cor de Lleó, ${ }^{19}$ però que en canvi reeixí a fer de la seva cort un punt de referència: Dalfí d'Alvèrnia, comte de Clermont i de Montferrand (II55/60-I235). De les vuit peces que va compondre, unes són de circumstàncies de caire humorístic i intranscendent, ${ }^{20}$ de vegades d'un humor més aviat agre, com, per exemple, el debat amb el seu cosí Robert, bisbe de Clermont, ${ }^{21} \mathrm{~d}$ 'altres són peces exclusivament polítiques (com el debat amb Ricard Cor de Lleó). També va participar en diversos debats amb trobadors de renom. La vida que li és dedicada el presenta com un "dels plus savis cavalliers, e dels pus cortes del mon, e dels larcs, e.l meiller d'armas, e que plus saup d'amor e de domnei e de guerra e de totz faitz avinenz, e.l plus conoissenz e.l plus entendenz, e que meilz trobet sirventes e coblas e tensos, e.l plus gen parlanz hom que anc fos a sen e a solatz. E per la larguesa soa perdet la meitat e plus de tot lo sieu comtat; e per avareza e per sen o saup tot recobrar, e gazaingnar plus que non perdet". ${ }^{22}$ Protegí trobadors com Peirol, a qui "vestia e.ill dava cavals et armas", i amb qui va debatre sobre si hom estimava millor abans o després del fet, ${ }^{23}$ Perdigon, a qui també vestia i armava "e.ill det terra et renda", i amb qui va tensonar sobre si una dama s'ha d'estimar més el cavaller vil o l'home cortès però nascut de vilan lignatge, ${ }^{24}$ Uc Brunenc, Uc de Sant Circ, Gaucelm Faidit. Li dedicaren

ig Ph. A. Becker, Dalfin d'Alvernhe, der Troubadour, Leipzig, 194I, pp. 40-48.

20 S. C. Aston, "The Poems of Robert, Bishop of Clermont", in Mélanges Rostaing, Lieja, 1974, pp. 25-39.

2I C. A. F. Mahn, Die Werke der Troubadours in provenzalischer Sprache, Ginebra, 1977, III, I32$\mathrm{I} 33$.

22 J. Boutière i A. H. Schutz, Biographies des troubadours, París, I950, p. 84.

23 R. Harvey, "Two partimens involving Peirol”, Cultura Neolatina, LXIV-I-2 (2004), pp. I87205 .

24 J. Marshall, "Le partimen de Dauphin d'Auvergne et Perdigon", in Mélanges Rostaing, 
cançons Guiraudó lo Ros, Giraut de Bornelh, Elias de Barjols, Uc de la Bacalaria, Raimbaut de Vaqueiras. ${ }^{25}$ Si les biografies de Peire de Maensac (protegit en els seus amors aventurers pel Dalfí) i de Peirol (enamorat de la germana del Dalfí, Salh de Clastra, "bella e bona e molt presada", i que engelosí el germà), i alguna razo que l'afecta directament (quan fou "drutz de na Comtor") no són fantasies més o menys gratuïtes, el Dalfí vivia en un ambient propici a la joia amorosa i a les lleis de la cortesia. És així que pot dir a Bauzan "q'ieu ai lo mestier avezat/ d'amor" ${ }^{26}{ }^{26}$ Totes aquests relacions, demostren, per dir-ho amb Saverio Guida, que foren molts els qui trobaren "nell'ospitale foyer di Montferrand il più avanzato e liberale punto di confronto, aggregazione e fecondazione dei fermenti, delle iniziative, delle sperimentazioni culturali che andavano maturando in una stagione per molteplici aspetti cruciale della storia del Midi" ${ }^{27}$ La seva llarga existència va fer pensar Alfred Jeanroy que justament cap al final dels seus dies, "il apparaissait comme le représentant attardé d'une époque disparue" i que és aleshores que el retrata Ramon Vidal. ${ }^{28}$ Tanmateix, el fet que aparegui com a jutge de partimens en anys en què encara no havia arribat a la vellesa, i que hom apel.li al seu saber - "lo Dalfins sap la via / et l'obra de cortesia", afirma Uc de la Bacalaria—, ${ }^{29} \mathrm{fa}$ que hàgim de creure que la seva fama d'home entès en afers cortesos era reconeguda i consolidada en els anys 90 del segle XII. No s'oblidi a més que ja Albertet havia dit "q'ieu vic qe.l Dalfiz fon plus pros / entendeir', enanz qe drutz fos". ${ }^{30}$ D'altra banda, el fet que el joglaret comenti que el Dalfí un cop conegut millorava la imatge que se n'havia format per la brama de la gent, fa pensar que la visita es produeix no gaire després de II99, quan amb la conquesta francesa la fortuna se li mostrà adversa, i fou l'autèntica causa de la seva ruïna. Per algunes poesies seves sembla que la relació amb els joglars — Mauret, Coindarel— fou estreta i sense grans distàncies. Giraut de Bornelh, en el sirventès al joglar Cardalhac, finalitza un reguitzell de consells burlescos recomanant-li que visiti el Dalfí, perquè amb ell no caldrà insistir gaire: "no.us chalra preiar, qu'el vos entenda".$^{{ }^{1}}$ El Dalfí el va rebre i va compondre un sirventès de resposta, Pos sai etz vengutz, Cardaillac,

Lieja, 1974, pp. 669-678; M. FÈvre, "Un nouveau regard sur le partimen entre Dalfi et Perdigon, Perdigons ses vassalatge", Revue de Langues Romanes, CXII-I (2008), pp. 73-8I.

25 S. Stronski, Le troubadour Elias de Barjols, Tolosa de Llenguadoc, 1906, pp. 476-483; F. DE LabareYre, La cour littéraire de Dauphin d'Auvergne des XIT et XIII siècles, Clermont-Ferrand, I976, pp. 73-78.

26 A. Kolsen, Trobadorgedichte, Halle, 1925, 5 b 5-6.

27 S. Guida, "Qüestioni relative a tre partimens provenzali”, Cultura Neolatina, LXvIII-3-4 (2008), pp. 249-309 (272-273).

28 A. Jeanroy, Histoire sommaire de la poésie occitane, Ginebra, 1973, pp. 26-27.

29 J. Mouzat, Les poèmes de Gaucelm Faidit, París, 1965, xLV, 75-76.

30 J. Boutière, Les poésies du troubadour Albertet, Torí, I969, XXI, 39-40.

3I Kosen, Trobadorgedichte, LXXV, 72. 
dient-li, però, que "Girautz sa·us mandet ben en van". Un altre d'aquests poemes - Ioglaretz petitz Artus — conté un conjunt de consells humorístics a un joglar jove i inexpert, la qual cosa fa del tot versemblant que el joglaret del nostre poema li demani la seva opinió. ${ }^{32}$

No és en principi descartable la idea que hi hagi hagut un temps particularment feliç per a la joglaria, que Linda M. Paterson situa en els anys finals del segle XII i justament en la zona que el poema de Ramon Vidal té en compte. ${ }^{33}$ De l'anàlisi de Paden, en canvi, que se centra en les apel-lacions a joglars en els poemes, es desprèn que el període de major activitat joglaresca es produeix entre II80 i I220. ${ }^{34}$ Meneghetti limita la durada de la fortuna dels trobadors, i hem de suposar que el paper dels joglars hi és inclòs, entre els anys 70 del segle XII i els primeríssims anys del XIII i que, al seu parer, no aniria més enllà en l'àrea catalano-provençal descrita a l'Abrils issia. ${ }^{35}$ Tanmateix no podem deixar de recordar, amb Saverio Guida i Stefano Asperti, ${ }^{36}$ que el regnat del rei Pere no comportà cap mena d'alteració. Al contrari, abunden els elogis a la seva extrema cortesia, i al tarannà modèlicament cortès del monarca, ${ }^{37}$ tant per part de trobadors com de joglars, molts dels quals, si Guiraut de Calansó té raó, van dient: "Pros reis es, ses falhir".$^{38}$ El fet que el seu fill digués d'ell críticament que "era hom de fempnes" (Llibre, 8), com, segons algunes vidas, ja ho havia estat el seu avi, i que gairebé el caricaturitzés assegurant, amb el testimoni de figures tan rellevants com Dalmau de Creixell o Arnau de Castellbò, que els nobles, per tal d'evitar que els llevés diners i privilegis, "mostraven-li lurs muylers e lurs fiyles e lurs parentes, les pus beles que podien trobar e feÿen-lo mudar en ço que els volien" (Llibre, 8), el que revela més que res és una profunda diferència entre el món de Jaume I, que no hauria entès el joc i el gust pel joc que comporta la cortesia, i el de Pere el Catòlic, que el representava en alt grau. ${ }^{39}$ Deuria ser una fama molt estesa: Guillem de Puy-Laurens assegura, amb testimonis, que hom havia interceptat una lletra del rei en què deia a una dama, casada amb un noble tolosà, que havia vingut a expulsar els francesos per amor

32 F. Witthoeft, Sirventes joglaresc, Marburg, I89I, pp. 42-44.

33 L. M. Paterson, El mundo de los trovadores, Barcelona, I997, p. Io8.

34 W. Paden, "The Role of the Joglar in Troubadour Lyric Poetry", a P. S. Noble i L. M. Paterson, Chrétien de Troyes and the Troubadours: Essays in memory of the late Leslie T. Topsfield, Cambridge, I984, pp. 90-III (95).

35 Meneghetti, Il pubblico dei trovatori, p. 48.

36 S. Guida, "Pietro il Cattolico ed i trovatori”, a V. Beltran, M. Simó i E. Roig (eds.), Trobadors a la península ibèrica, Barcelona, 2006, pp. 223-240; S. Asperti, "I trovatori e la Corona d'Aragona", Mot so razo, I (1999), pp. I2-3I (I5).

37 Guida, "Pietro il Cattolico ed i trovatori", p. 236.

38 W. ERnst, "Die Lieder des provenzalischen Trobadors Guiraut von Calanso", Romanische Forschungen, XLV-2 (1930), pp. 255-406 (III, 44).

39 S. M. Cingolani, Jaume I. Història i mite d'un rei, Barcelona, 2007, p. 72. 
d'ella. ${ }^{40}$ No s'oblidi, però, que Gui d'Ussel s'havia adreçat al rei Pere assegurant que "dompnejan e meten / ...conqueretz pretz valen". ${ }^{4 r}$

En aquest punt, el decisiu és que l'univers mental i sentimental que visqué el rei Pere el col-loca en el mateix espai en què se situaven els trobadors. I en són la prova l'aventura de Raimon de Miraval, que veié amb gran disgust com el rei li prenia una dama, i molt probablement aquests versos d'Aimeric de Sarlat, que tement-ne la competència, escriu, pensant en les sol-licitacions de què pot ser objecte la seva dama (Aisi mueu mas chansos): ${ }^{42}$

Neus del bon rei prezan

d'Aragon, c'a pretz guai, sobre tot no volria

agues sa drudaria

Per coherència amb el meu plantejament, vull entendre que el temps que el joglaret tanmateix més que enyorar voldria revifar plenament no és un temps mític, sinó un temps històric, la qual cosa no exclou, és clar, que tot plegat vessi fortes dosis d'idealisme: la plenitud ideal s'hauria produït en el temps de Ramon Berenguer IV —el "pros coms de Barcelona" del v. 869-, o sia en els mateixos anys en què Dante a la Vita Nuova situa els inicis de la lírica en llengua vulgar: "se volemo cercare in lingua d'oco e in quella di sì, noi non troviamo cose dette anzi lo presente tempo per cento e cinquanta anni" (xxv). No hi pot haver dubte en aquest punt (vv. 876-878):

Et e.l temps d'aquestz se levero qu'ieu vos ai dig, li trobador e soudadier e contador

Segons el marc cronològic en què ens movem, la distància és només d'uns 70 anys — "picciolo tempo", deia Dante força més tard—, no un temps boirós i remot del qual hom rep una imatge idíl.lica de contorns imprecisos i sense contacte possible amb el món actual. El moment inicial, aleshores, seria aquell en què la realitat responia a allò que deien els poemes i viceversa. Sembla com si hom percebés que en aquell temps no tan llunyà alguna cosa es va transformar definitivament, i va prendre una nova i acabada forma, en la llengua, en les sensibilitats, en les expectatives històriques de futur, i va deixar enrere un magma ple

40 G. Puy-Laurens, Histoire de l'expédition contre les albigeois, Clermont-Ferrand, 2004, p. 46.

4I J. Audiau, Les poésies des quatre troubadours d'Ussel, Raphèle-lès-Arles, I993, II, 53-54.

42 M. Fumagalli, "Le canzoni di Aimeric de Sarlat", Travaux de Linguistique et de Littérature, XVII-I (I979), pp. I2I-I69. (I, 5I-54). 
de potencialitats però ja no nítidament captable. $\mathrm{O}$ només captable com a fase primitiva de la civilització present. Aquest temps anterior, que des del punt de vista literari aniria des del voltant del $950^{43}$ fins al mateix Guilhem IX, correspondria a la descripció de Rodolf el Glabre a les anomenades Cròniques de l'any mil dels aspectes de moda i conducta dels nobles d'Aquitània i d'Alvèrnia arribats a França pel casament del rei Robert amb l'aquitana Constança, qualificades pel cronista de perverses i immorals. ${ }^{44}$ Fóra també el temps en què, a propòsit d'un element clau com és el model de dona, Pierre Bonnassie exemplifica, amb el cas d'Almodis de la Marca, comtessa de Tolosa, raptada, amb el seu consentiment, per Ramon Berenguer I, "una tendència, perceptible en casos aillats, que trigarà unes tres generacions a prendre cos". ${ }^{45}$ Just en els temps de Ramon Berenguer IV.

Si és obvi que aquest enfocament permet un grau d'idealisme força alt, ja que concep la història com l'aprenentatge imitatiu del passat — d'un passat que de manera exemplar se sintetitza en un instant pletòric_-, supura al mateix temps un grau de pessimisme no pas de baix nivell, en la mesura que, a semblança de tot Edèn, no hi ha història sense pèrdua. I si és igualment clar que aquesta convicció és la que permet d'assenyalar una distància que afavoreix la funció i l'eficàcia de la crítica i del discurs didàctic, no és menys cert que des dels començaments de la lírica trobadoresca, amb Marcabrú, Bernart Martí o Cercamon, la ideologia cortesa sempre ha estat en crisi en el discurs dels moralistes, ni que sigui per una qüestió merament tàctica. I, significativament, el repertori del joglaret demostra que aquesta distància no és sentida com una pèrdua irremeiable, per la senzilla raó que allò que canta de nostàlgic no en té res. Vull dir que el seu repertori no implica una disposició al revival o l'enyor. ${ }^{4}{ }^{4} \mathrm{La}$ nostàlgia no és el seu tema. El problema és fer escoltar en el present els autors del dia. Ell canta Giraut de Bornelh, un clàssic modern, Arnaut de Maruelh — que serà combatut a So fo e.l temps—, i s'ha introduït en l'ofici amb les composicions del Dalfí d'Alvèrnia, un estricte contemporani no especialment crític amb res. I no podem creure de cap de les maneres que viu abocat al passat si el primer que diu és que el seu repertori està ocupat majoritàriament per la narrativa (vv. 40-42):

Say romans dir e contar, e novas motas e salutz e autres comtes

43 Paden, "The Role of the Joglar...”, p. 526.

44 G. Cavallo i G. Orlandi, Rodolfo il Glabro. Cronache dell'anno mille, Milà, 1990, p. 40.

45 P. Bonnassie, Catalunya mil anys enrere, Barcelona, 1979, p. 444.

46 J. Rodríguez Velasco, "'Yeu suy un hom aclis / A joglaria de cantar'. O de la educación trovadoresca del juglar”, Mot so razo, I (1999), pp. 40-5I (45). 
És a dir, gèneres que aleshores eren no només una novetat, sinó que constituïen el fenomen de renovació més impactant de la literatura occitana. El joglaret, no hi ha dubte, estava au dernier cri. Fóra d'altra banda estrany que qui coneix tan bé el seu ofici no ho estigués.

I llavors? Quin és el problema, que exigeix, com es dedueix de l'exemplum arabitzant del Dalfí d'Alvèrnia, una política de regeneració dels valors i les actituds fundacionals? El joglar i el seu mestre critiquen qüestions d'ordre divers. D'entrada, la formació del joglar. Vers II9: n'hi ha que "ses autrui saber son joglar". L'afer és important perquè el joglar tal com aquí se'l tracta és, com ja va dir Limentani, "latore di verità, di una verità che non vale in se stessa, ma si deve riflettere como forza educatrice della società cortigiana. Funzione specifica del giullare è quella di diffusore della letteratura-civiltà". ${ }^{47}$

Però si la formació de la joglaria és un problema cabdal — i Vidal hi insisteix esmentant la mala educació i els baixos continguts de les històries i cançons, els mals capteniments, la manca d'elegància en les maneres, com també se'n queixarà Aimeric de Peguilhan ("Li fol e.il put e.il filol / creison trop e no m'es bel / e.il croi joglaret novel / enojos e mal parlan”, XxxII, I-4)—, no deixa de ser rellevant que enlloc no es digui una sola paraula sobre quin hauria de ser el currículum que un joglar hauria de seguir per tal de resoldre'l. En això se separa, per exemple, del que s'esdevé a Daurel e Beton, on podem seguir els passos del peculiar joglaret Betó en el seu període formatiu que comprèn dels 6 anys als $\mathrm{I} 3$, i que va de la música a les armes. Betó, fill de Boves d'Antona, és educat pel joglar Daurel que el puja a partir d'un recorregut cortesà únic, és a dir vàlid per al joglar i per a l'aristòcrata. En aquest punt que sembla reunir la cort al voltant d'uns mateixos coneixements i d'unes mateixes necessitats, el grau de coincidència final amb el nostre text és notable. Ultra la precocitat, em sembla remarcable que la primera pedra de l'edifici educatiu de qui està destinat al govern i a la guerra i es disfressa de joglar, convingui tant a aquest darrer: $4^{48}$

Quant ac vij ans Beto sap gen violar, e tocar citola e ricamen arpar e cansos dire, de se mezeis trobar.

L'absència de qualsevol menció al sistema educatiu és digna de ser subratllada. Hem de concloure, doncs, que el joglaret de l'Abrils issia s'ha format sobre el terreny, viatjant amb el seu pare, el record del qual, per cert, és encara viu a la cort d'Hug de Mataplana. Som, doncs, lluny de la queixa de qui, com Cerverí,

47 A. Limentani, L'eccezione narrativa, Torí, 1977, p. 56. 48 Ch. Lee, Daurel e Beton, Torí, I99I, pp. I4I9-I42I. 
assegura que "Trop m'enug de cortz anar / e de joglaria, / e de porters sopleyar".49 En aquesta educació nòmada, només la pràctica, la disposició, la capacitat d'elecció de corts elevades, els contactes amb la gent entenimentada i l'entrenament d'un cert olfacte psicològic proporcionen el saber que cal al joglar (vv. 960-963):

$$
\begin{aligned}
& \text { Joglaria vol home gay } \\
& \text { e franc e dos e conoisen, } \\
& \text { e que sapcha far a la gen, } \\
& \text { segons que cascus es, plazer. }
\end{aligned}
$$

El particular saber del joglar, i que fa que el seu ofici sigui "nothing less than a subtle pedagogy", so reposa sobre tres principis: ardiment, manieira i sen. Per ardiment crec que cal entendre esperit de superació, fruit, com deia Ramon Llull a la Lògica nova definint l'audàcia, de la "nobilitat de la ànima movent lo cors a aquelles coses per les quals pusca haver nobles actes", ${ }^{\text {,I }}$ altrament dita fortitudo; per manieira la capacitat de discernir, la qual cosa la col-loca al costat de la filosòfica prudentia, que en d'altres textos pot expressar-se amb el mot conoissensa, ${ }^{52}$ i per seny —que no és rar que expressi també la idea de prudència—s3 l'exercici de la mesura perfeccionat a la pràctica de la vida, per la qual cosa no li podem aplicar la idea clerical de sapientia, que sol acompanyar la idea de fortitudo, i hem de postular una saviesa de naturalesa diferent. És altament remarcable que Ramon Vidal no s'aculli a cap dels tòpics que emparen la transmissió del saber i que són tan freqüents en la cultura literària tocada de clerecia. Demostrant que el seu univers és exclusivament laic i cortès, no fa com els primers narradors en llengua d'oïl, que orgullosos de la seva funció i del seu superior saber clerical, es presenten com a baules d'una cadena on hi ha els noms més prestigiosos del món clàssic i de la tradició bíblica que han conegut en la llengua sàvia.

Però tampoc fa com Arnaut de Maruelh, que en la mateixa línia situa el seu Ensenhamen sota la protecció de Salomó, Plató, Virgili o Homer. ${ }^{54} \mathrm{Ni}$ com farà més tard Sordel en el seu Ensenhamen d'onor recordant que el saber ocult no val

49 M. DE Riquer, Obras completas del trovador Cerverí de Girona, Barcelona, I947, XxX, I-3.

50 V. M. Wilhite, "Instructing the Court: Raimon Vidal's Pedagogy for the Courtly joglar", a C. Kleinhenz i K. Bosby (eds.), Courtly Arts and the Art of Courtliness: Selected papers from the Eleventh Triennial Congress of the International Courtly Literature Society, Cambridge, 2006, pp. 755-770 (768).

5I A. Bonner, Ramon Llull. Lògica nova, Palma de Mallorca, 1998, p. 78.

52 A. H. Schutz, "Some Provençal Words Indicative of Knowledge", Speculum, 33-4 (1958), pp. 508-5I4 (5I4).

53 CH. Brucker, Sage et sagesse au Moyen Âge (XII et XIII siècles), Ginebra, 1987, p. 323.

54 M. Eusebi, "L' Ensenhamen di Arnaut de Mareuil", Romania, xc (I966), I4-30. 
res." 5 Si ho interpreto bé, el joglar, aleshores, se'ns apareix com una mena particular de filòsof que no ha necessitat entrar a cap aula, on tots aquests conceptes prenen un altre relleu. O millor encara, el joglar, que és tractat d'igual a igual pel savi trobador Vidal de Besalú, és el primer dels cortesans. Modest per l'origen i noble per la funció, se li podria aplicar el que Benvenuto da Imola va dir d'Arnaut Daniel: "vir quidem curialis", i que Chabaneau traduïa com "joglar, home de cort".

El segon problema que s'esmenta és el de la pèrdua de generositat, que impedeix que el joglar sigui obsequiat amb arnesos, robes luxoses o frens daurats. La manca de llarguesa s'atribueix de fet a diverses causes: al desinterès d'alguns pels gèneres més refinats, al fet que els grans senyors ja tenen joglars en nòmina i no atenen el que se'ns dibuixa com un joglar ambulant, a la gasiveria d'uns altres. En aquest sentit és prou revelador el sirventès contra els joglars d'un professional del cant que estigué a "Monferrat en Peimont ab miser Ot del Carret, et a Cortemilla", Peire de la Mula::
Dels joglars servir mi laisse seignor, aujatz per que ni com: car lor enois creis e poja e qui mais los serv mescaba
e son ja tant pel mon cregut que mais son que lebret menut.
Lor affars cuich que abasisse, car ill son plus pesan que plom et es en mais que de ploja

I igualment ho és que un altre joglar, Guilhem Magret, clami contra el desinterès del públic, que és l'altra cara de la moneda: ${ }^{57}$

Non valon re coblas ni arrazos ni sirventes; tan es lo monz deliz qe per dos solz serai meillz acollitz si.ls port liatz en un de mos giros, que per cent vers ni per doz cenz cansos.

55 M. Boni, Sordello, le poesie, Bolonya, 1954, pp. I-9.

56 G. Bertoni, I trovatori d'Italia, Roma, I967, XI, I-II.

57 F. NAudieth, "Der Trobador Guillem Magret”, Beihefte zur Zeitschrift für romanische Philologie, 52 (I9I4), pp. 8I-I44 (V, I-5). 
Sembla que s'està entrant en un cercle viciós. La proliferació de la joglaria, amb el consegüent intrusisme i la inevitable pèrdua de qualitat, hauria saturat els mercats $\mathrm{i}$ anul.lat aquell interès que hi abocaven els magnats i feia rendible la professió, mentre els trobadors veurien com la lírica de qualitat, confosa entre repertoris de circumstàncies, no aconseguiria d'atreure un públic que s'havia tornat desconfiat. S'inicia, doncs, un problema que esclatarà del tot a finals de segle i es farà patent en l'obra d'un Cerverí de Girona i sobretot d'un Guiraut Riquier. Els quals, d'altra banda, estan marcats pels anatemes eclesiàstics contra la joglaria, ${ }^{58}$ que a la Corona d'Aragó no es produeixen fins a les corts de Tarragona de I235, i dels quals Ramon Vidal es troba completament al marge.

La dificultat de trobar un públic atent, amb el gust educat i una certa cultura no és una temàtica exclusiva de Ramon Vidal. De fet, en el seu temps l'expressen trobadors com Elias Cairel, Guiraut de Calanson o Peirol. Marshall creu que aquestes actituds suposen un rebuig al trobar ric, tot i que tal com ho tracta Ramon Vidal sembla que l'afer va més enllà de limitar-se a una qüestió d'estils.

Pel que fa a la dimensió econòmica de la crítica, és fora de dubte que el regnat de Pere el Catòlic va ser, des del punt de vista econòmic, un desastre monumental, com a resultat de les contínues guerres en terra occitana i, sobretot, del cens que va haver de pagar a la Santa Seu com a vassallatge després de ser coronat pel papa, car, com ha escrit Enric Bagué i ha corroborat Martí Aurell,s9 es va veure "arrossegat a una ruïnosa política econòmica que exhaurí els seus recursos i espolià els seus dominis i els seus súbdits". ${ }^{60}$ Però els problemes venien d'abans. El Libre dels reis reporta que "lo dit rey en Pere d'Aragó sí avia enpenyorade la sua corona d'or per la vengude de Roma, he no sabia quin consell hi donàs. Però a la fi ell pensà en si mateix tal consell, que féu fer una corona fort meravellosament feta de paste de forment, recolade e lise, he de sobre ab fulla d'or cuberta". ${ }^{61}$ L'anomenada Crònica llatina dels reis de Castella assegura no va poder pagar el viatge a Las Navas, ja que "pauper enim erat, et multis debitis obligatus". ${ }^{62}$ La versió catalana dels Gesta Comitum comença l'anotació del seu regnat dient que "fo bon d'armes, cortès e larch, en tant que ciutats, castells e viles e tot ço que podia obligava", ${ }^{6_{3}} \mathrm{O}$

58 Veg. E. Faral, Les jongleurs en France au Moyen Âge, París, i97i; C. Casagrande i S. Vecchio, "Clercs et jongleurs dans la société médiévale", Annales, 34-5 (1979), pp. 913-928; J. W. BALdwin, "The Image of Jongleur in Northern France around I200", Speculum, 72 (1997), pp. 635-663; W. Noomen, Le jongleur par lui-même. Choix de dits et de fabliaux, Lovaina i Paris, 2003.

59 M. Aurell, Les noces del comte, Barcelona, 1998, p. $4 \mathrm{I} 3$.

60 E. Bagué, "Pere el Catòlic", in E. Bagué, J. Cabestany i P. E. Schramm, Els primers comtes reis, I980, pp. IO7-I52 (II6),

6i S. M. Cingolani, Libre dels reis, València, 2008, ClXXIX, 210.

62 M. De los D. Cabanes, Crónica latina de los reyes de Castilla, Saragossa, 1985, p. 36.

63 S. M. Cingolani, Gestes dels comptes de Barcelona i reis d'Aragó, València, 2008, pp. I25-I26. 
sia empenyorava per exercir la liberalitat, que era per a ell, com a encarnació dels valors de la cavalleria, la virtut més decisiva, absolutament irrenunciable, perquè era aquella on es jugava l'ésser i la fama, principi primer de la seva personalitat i de la seva acció política. El seu fill li va reconèixer la virtut, però no n’amagà les penoses conseqüències: "Nostre pare lo rey en Pere fo lo pus franc rei que ans fos en Espanya, e el pus cortès e el pus avinent, sí que tant donava que ses rendes e ses terres ne valien menys" (Llibre dels fets, 6). Soldevila ho resumeix en un sol mot: bancarrota. ${ }^{64}$ No descartaria, aleshores, de veure en la crítica a la manca de generositat un suport indirecte a la manera de procedir del monarca, en qui els trobadors del seu temps veieren l'encarnació de la cortesia. No s'oblidi que tots els magnats catalans esmentats o els seus llinatges van ser fidels al seu pare en la rebel.lió de la noblesa. Crec, doncs, que la sospita que el moment no era econòmicament favorable a grans dispendis és del tot versemblant.

Hi ha encara un altre aspecte, que irromp en els versos dedicats a les dames, que són els més inquietants de tot el poema. D’entrada, perquè provoca estupefacció que en un text on gairebé tots els homes han estat degudament localitzats, i sense gaires indagacions, les dames catalanes siguin un autèntic enigma. Ningú no sap qui és "Na Matieus del Palars", ni "la dona d'en Gelmars", ni quina pot ser amb exactitud la comtessa d'Urgell i menys encara "na Gensana" esmentades als versos 915-918. La primera no s'ha documentat, la segona és, com diu Field, el resultat d'una distorsió, mentre que per a l'última Antoni Comas, seguint Milà i Bergert, va suggerir una mala lectura de Jussiana, que s'identificaria amb Jussiana d'Entença, mare del comte d'Empúries i tractada amb respecte per Guillem de Berguedà, la qual cosa, segons Field, no passa de ser una solució "massa feble".

L'important, però, és que Ramon Vidal les fa responsables del poder creixent dels homes de religió en els àmbits cortesos. I en aquest punt em sembla que hi ha un dels centres nuclears que de manera tan remarcable com discreta es troben en els fonaments del poema. Va ser Linda Paterson qui va dir, comentant els versos que descriuen la conducta de les dames, que "Raimon Vidal, en la época de la derrota occitana de Muret, achaca la responsabilidad por la decadencia de la vida cortesana al clero, que no admitía ya la coexistencia pacífica entre valores cortesanos y religiosos, y presionaba a los nobles para que cambiasen las enseñas de las damas por rosarios". ${ }^{65}$ Monica Calzolari és del mateix parer quan diu que Ramon Vidal en amplificar les causes que han conduït al deplorable estat present "sembra mettere in relazione l'indebolimento dell'aristocrazia e dell'autorità regia col sopravvento assunto da altre forze legate alla Chiesa, portatrici di valori diversi ed antagonisti a quelli cortesi" (89). Jordi Ventura ha insistit en la idea que "l'an-

64 F. Soldevila, Cronistes, joglars i poetes, Barcelona, I996, p. 92.

65 Paterson, El mundo de los trovadores, p. Ioo. 
ticlericalisme dels feudals catalans de la segona meitat del XII és indubtable". ${ }^{66}$ Arriba clarament als primers anys del segle següent i el nostre trobador no dubta a fer-se'n portaveu.

Els versos no són del tot clars, i a més el manuscrit presenta en aquest punt una llacuna, però el sentit que se'n desprèn és que en temps de Ramon Vidal hi havia dames tan distingides, o sia tan influents i de tant relleu com les esmentades, que pertanyien a una època anterior - i que essent laiques havien donat, tanmateix, exemple ultrancer de fe i privilegiat la companyia dels clergues, lligada a les seves fundacions religioses-, mentre que ara, en canvi, les dames s'allunyaven d'antigues converses i d'altres conductes, i d'altres ocupacions i d'altres ensenyaments cortesos, també igualment profitosos, i per a Ramon Vidal més convenients. Aquell capteniment que feia dir a Bertran de Born, lloant Matilde, filla d'Enric II i Elionor d'Aquitània: "de solatz mi semblet catalana”. ${ }^{67} \mathrm{La}$ impressió que fa el paràgraf és que si les cita és perquè aquestes dames, posades com a exemple, s'hi havien resistit, honorant l'església, però sense renunciar al món: "ses que no volgron obezir" (v. 924). Això em fa pensar que es tracta de dames que són vídues, un estat que l'Església equipara al de les monges, com explicarà més tard Eiximenis al Libre de les dones, i que ja al segle XII l'Església "les incitait à s'enfermer dans un cloître". ${ }^{68}$ Les dones, d'altra banda, semblen haver estat l'objectiu preferent de l'acció eclesiàstica, particularment de Domingo de Guzmán i els seus, com una manera de contrarestar la influència que hi havien tingut els predicadors càtars. ${ }^{69}$ "L’on est frappé — escriu Anne Brénon en el mateix sentit- par le rôle préeminent des femmes de la petite noblesse occitane que les documents unanimes laissent entrevoir", en l'acolliment i l'atenció dispensada als predicadors càtars, i aquestes dames "purent prêter sans difficulté apparente une oreille à des débats amoureux parfois un peu futiles, et l'autre aux austères admonestations évangeliques des Bonshommes". $7^{\circ}$

La realitat actual, la del temps de composició del poema, però, ben al contrari, ve determinada per un fet sens dubte molt nou (plenament acceptat, per exemple, per Cerverí: Fyll, eras pus en escolas anatz), ${ }^{71}$ i que és difícil de separar del clima de pressió religiosa previ al fatídic I2I3. També en el mateix clima i per aquelles dates Guilhem Rainol d'At es queixava que els poderosos es deixessin abassegar pels cler-

66 Ventura, Els heretges catalans, p. 65.

67 G. Gouiran, Le seigneur-troubadour d'Hautefor. L'oeuvre de Bertran de Born, Ais de Provença, I987, II, 3I.

68 G. Duby, Dames du XII siècle, París, I995, II, 217.

69 M. Roquebert, L'épopée cathare, Tolosa de Llenguadoc, 200I, pp. I75-I8I.

70 A. Brénon, "Fin'amors et catharisme", a V. Cognazzo i G. Macchia di Coggiola (eds.), Peire Guilhem de Luserna e lo tems dals trobaires, Piasco (Cuneo), I994, pp. I4O-I4I.

7I RiQuer, Obras completas del trovador..., LXXXVIII i XIV. 
gues (Laissatz miera de chantar)..$^{72}$ I el fet nou és que els plançons de la noblesa són pressionats per ser sotmesos a un altre procés educatiu, el control del qual escapava a la mà dels laics, davant la inacció dels mateixos poders seculars (vv. 932-935):

E car trobon comtes e reys

E poestatz feblas e molas

han los tornatz en lurs escolas

e fan lur creire so que.s volon.

El conflicte amb la moral que l'Església malda per imposar, i les expressions de resistència no són exclusives de la cultura meridional. Al Guillaume de Dole el rebuig s'expressa d'una manera directa i sense embuts, referida, a més molt clarament, a les conductes eròtiques, fonamentals en la mentalitat laica: ${ }^{73}$

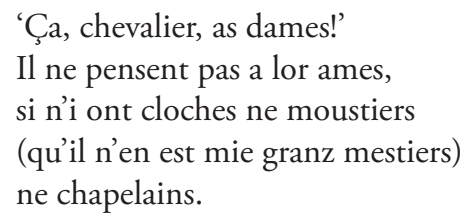

Però això, tanmateix, no ho acaba d'explicar tot. El problema al qual es fa referència més sovint és la pèrdua de paratge. En el poema apareix en contextos diversos que no s'allunyen d'un mateix camp de significació que crec que no podem entendre que designi — i vet aquí un altre element per a datar — "collectivament els nobles occitans i les seves terres, la pàtria occitana”, com ha escrit Zambon respecte de la Canso de croada, i tan vibrantment invocat per Gui de Cavalhon, ${ }^{74}$ sinó, com indica el mateix Zambon, el seu fonament: "noblesa, coratge, esperit cavalleresc",75 i que en el poema de Ramon Vidal és descrit com un dels impulsos fundacionals (vv. 264-266), no desvinculable, per cert, del sorgiment de la literatura en llengua vulgar, car dels seus posseïdors "feron chansons / e fon solatz fag e trobat" (vv. I642-43). Ho confirma, i ho pren com un estímul, uns pocs anys més tard, Guilhem de Montanhagol: ${ }^{76}$
Non an tan dig li primier trobador ni fag d'amor, lai el temps qu'era guays

72 M. DE RiQuer, Los trovadores. Historia literaria y textos, Barcelona, I975, III, LXXV.

73 F. LeCoy, Jean renart. Le roman de Guillaume de Dol, Paris, 2008, pp. 223-227.

74 E. Martin СНавот, La chanson de la croisade albigeoise, París, 1972, II, I54.

75 F. Zambon Paratge, Els trobadors $i$ la croada contra els càtars, Barcelona, 1998, p. 30.

76 P. T. Ricketts, Les poésies de Guilhem de Montanhagol, Toronto, 1964, VIII, I-3. 
Donem-hi relleu: no hi pot haver literatura en llengua vulgar (afer de trobadors, per qui "tot lo be e lo mal del mon es mes en remembrança de les genz", com es diu a les Razos de trobar), ni, ja que hi som, joglaria, que és la cirereta del solaç, sense paratge. Aquest moment inicial és el vertader temps en què hom era feliç. Ho assegura, amb adolorit pessimisme, Giraut de Bornelh: ${ }^{77}$

Molt era dolz e plazens
lo tems gais, can fon eslitz
paratges et establitz;
que.ls drechurers, conoissens,
leials, francs, de ric coratge,
plazens, larcs, de bona fe,
vertaders, de gran merce
establit om de paratge,
per que fo servirs trobatz,
cortz e domneis e donars,
amors e totz ben estars
d'onor e de gran drechura.

Ara bé, paratge no és una qualitat que s'hereta. Aquesta és una idea en què s'insisteix diversament, amb l'autoritat de l'Ensenhamen d'Arnaut de Maruelh al darrere. Paratge depèn d'una parella molt coneguda, com ja va explicar Schutz, com la que formen pretz e valor, que segons exposa el joglaret al Dalfí, ha perdut la noblesa contemporània. La resposta del Dalfí conté uns ingredients que mereixen ser destacats. Al seu parer, per tal de mantenir pretz cal "nobles cors e sens e sabers". Per la definició que en fa és possible de deduir que noble cor depèn de la qualitat de prous, d'on davallen l'ardiment, la llarguesa, la gentilesa, la lleialtat, la netedat d'ànim. El saber, que no es troba a l'abast de tothom, i que ajuda a distingir el bé del mal, i que a manca d'explicitacions hem de suposar que s'adquireix o es perfecciona a la cort, es tradueix en els "bells capteniments" (v. 255) que converteixen un home en algú "adreitz, francs e de solatz", que són qualitats públiques, de govern fins i tot, però sobretot corteses, mundanes, que acaben de definir una manera de ser perquè subratllen una manera d'estar en el món. Mentre que el sens és el responsable de la possessió de mesura.

$\mathrm{Si}$ ara recordàvem què havia dit Ramon Vidal sobre el saber, facilment arribaríem a la conclusió que la seva definició de saber s'assembla molt a la definició de pretz del Dalfí, i que la pèrdua de l'un i la pèrdua de l'altre no és solament que siguin contemporànies, ni conseqüència una de l'altra, sinó que són en el fons la mateixa pèrdua. I que ni el saber ni la fama no són res al marge de la idea més

77 Kolsen, Trobadorgedichte, LXIV, I-I2 
potent de totes, vertader estímul i origen de la civilització cortesa, que és l'amor. Si el saber "vol hom ferm ses mentir / adrey e franc e conoissen" (vv. 988-989), a So fo e.l temps és amor qui "non es als / mas ferms volers en om lials / e sens engan" (vv. I379-I382). Ramon Vidal, no hi ha dubte, aplaudiria un afirmació tan nítida com la que fa un teòric tan influent com Aimeric de Peguilhan (xx, I-3):

De fin'amor comenson mas chansos

plus que no fan de nulh'autra sciensa, qu'ieu non saubra nien s'amors non fos.

És a dir, i resumint, el poema de Ramon Vidal seria la queixa, més que la lamentació, per no poder bastir un univers laic, basat en un concepte de saber abocat a la vida de cort, fora del control del saber eclesiàstic i també del saber tecnificat i autònom, superbament convençut de la seva solidesa, aquella mena de saber que s'exposa al Tezaur de Peire de Corbian, que no dubta a exhibir amb orgull el seu lligam amb les universitats, i que acabarà per alterar i desplaçar el discurs sobre la pedra angular de tot l'edifici, que constituïa l'objecte preferent de la seva reflexió, que és l'amor. Tanmateix cal reconèixer que aquest saber que plau a Vidal, vinculat a la vida noble, a l'ideal de paratge, era aleshores difícil de sostenir i portar a la pràctica perquè una conjuntura on es barreja tensió política, tensió religiosa i crisi econòmica ho obstaculitza poderosament. Amb un greu problema afegit, $\mathrm{i}$ en el fons irresoluble: el saber que Ramon Vidal defensa no es transmet a l'escola, sinó sobretot en aquesta escola distinta i alternativa que és la cort, en un ambient distès, quan no francament de festa, bigarrat, sorollós i mogut, en el qual escoltar i aprendre és per la naturalesa mateixa de les coses d'una notable dificultat, car és pràcticament impossible aconseguir l'atenció unànime d'una gran diversitat de caràcters i d'interessos. Quan 50 anys més tard, els trobadors es posin seriosos i reclamin un silenci tot nou, professoral, com Cerverí de Girona, com At de Mons, com Guiraut Riquier, com Matfre Ermengaud, ho faran adoptant un posat clerical i un to de dómine que farien sentir a Ramon Vidal, malgrat les coincidències, que havia perdut la partida. I que l'havien guanyada, i de forma inapel-lable, aquells que havia combatut, els quals, com havia escrit Guilhem Rainol d'At, havien "bastit un segle nou". 